\title{
Expression of the porcine lipoic acid synthase (LIAS) gene in Escherichia coli
}

\author{
W.F. Lu, J.J. Cao, Y.J. Guo, K. Zhong, G.M. Zha, L.F. Wang and \\ G.Y. Yang
}

Key Laboratory of Animal Biochemistry and Nutrition, Ministry of Agriculture, Henan Agricultural University, Zhengzhou, Henan, China

Corresponding author: G.Y. Yang

E-mail: 5639400@qq.com / 1lwwff20000@163.com

Genet. Mol. Res. 13 (3): 5369-5377 (2014)

Received May 27, 2013

Accepted September 18, 2013

Published July 24, 2014

DOI http://dx.doi.org/10.4238/2014.July.24.16

\begin{abstract}
Lipoic acid synthase, which exists primarily in mitochondria, participates in the biosynthesis of intrinsic lipoic acid. The lipoic acid synthase gene in pig is known as LIAS. To further investigate the biological functions of the protein that is encoded by LIAS, we cloned the open read frame of porcine LIAS (GenBank No. JN797612.1) into the expression vector pET-28a(+). The resulting pET-28 $\alpha(+)$-Lias recombinant vector was introduced into the Escherichia coli BL21 (DE3) strain. With induction by isopropyl $\beta$-D1-thiogalactopyranoside, the recombinant $E$. coli strain can express the target protein that has a molecular weight of $41.58 \mathrm{kDa}$, which was confirmed by Western blotting.
\end{abstract}

Key words: Porcine lipoic acid synthase (LIAS);

Prokaryotic expression 


\section{INTRODUCTION}

Lipoic acid was originally discovered as a biotic factor in yeast, spinach, and multiple types of meat. Its primary biological activity is as an antioxidant. So far, it is the only antioxidant that has activity in both water and lipid. The IUPAC name of lipoic acid is 6,8-thioctic acid, and it contains a single-intramolecular disulfide bond. Lipoic acid serves as the cofactor for a variety of key enzymes in metabolism including pyruvate dehydrogenase, oxoglutarate, branched chain $\alpha$-ketoacid dehydrogenase, 3-hydroxybutyrate dehydrogenase, and glycine cleavage system (Cronan et al., 2005; Ghibu et al., 2008). Lipoic acid can not only interact with multiple oxygen-containing free radicals but also coordinate with different types of heavy metals (e.g., copper, iron, and mercury), which can protect organs and tissues (Melhem et al., 2002; Holmquist et al., 2007). Meanwhile, researchers have revealed that lipoic acid can accelerate the glucose metabolism cycle in mitochondria, affect the body's metabolism, boost the immune system to alleviate inflammation, and initiate cell repair pathways (Christensen et al., 2011). Recently, lipoic acid captured a significant amount of attention because of its function as an antioxidant and its role in treating diabetes complications (Packer et al., 2001).

The synthesis of lipoic acid takes place in mitochondria, in which caprylic acid is transferred to acyl carrier proteins (ACP) to form a caprylic acid-ACP complex. Under the catalysis of a specific enzyme, 2 thiols are introduced to the C6 and C8 of caprylic acid-ACP to form lipoic acid. This specific enzyme is called lipoic acid synthase (LIAS) (Rock, 2009; Hiltunen et al., 2010; Christensen et al., 2011). LIAS is a highly conserved enzyme in both prokaryotes and eukaryotes. Some studies demonstrated that lipoic acid malnutrition that was caused by genetic defects of LIAS could be reversed by salvation pathways (Morris et al., 1994; Crawford et al., 2006). However, eukaryotes strictly rely on the resynthesis of lipoic acid in mitochondria. In a study by Sulo and Martin (1993), the researchers found that LIASmutated Saccharomyces cerevisiae could not utilize the lipoic acids that were added in the culture medium. At the same time, Yi and Maeda (2005) confirmed that the feeding of lipoic acid could not improve the early-stage embryo lethality rate in LIAS knock-out mice.

Currently, several studies were undertaken to explore different biological functions of lipoic acid; however, information about lipoic acid participation in mammalian metabolism is rather limited. This is the major reason that LIAS-related research is highly desired (Morikawa et al., 2001). In recent years, the structural and functional research of plant, human, and murine LIAS has been prosperous, but reports about porcine LIAS are limited. In this study, in silico elongation and reverse transcription polymerase chain reaction (RT-PCR) were adopted to clone the porcine $L I A S$ gene and the target gene was successfully expressed in a prokaryote.

\section{MATERIAL AND METHODS}

\section{Animals and sample collection}

Four healthy hybrid decendents from Duroc, Danish Landrace, and Yorkshire-Large White pigs were used as experimental samples (acquired from Yongkang farm, Kaifeng, China). Liver tissue that was obtained from pigs was freshly dissected, frozen in liquid nitrogen, and stored at $-80^{\circ} \mathrm{C}$. 


\section{Total RNA isolation and cDNA synthesis}

Total RNA was isolated from $0.1 \mathrm{~g}$ frozen porcine liver tissue using Trizol (GibcoBRL, Germany) according to manufacturer instructions. All extracted RNA samples were dissolved in RNase-free water. The purity and quantity of total RNA were measured with an ultraviolet/visible spectrophotometer (NanoDrop 2000/2000C, USA). First-strand cDNA was synthesized using MMLV reverse transcriptase (Promega, USA), $\sim 3 \mu \mathrm{g}$ RNA, and an oligo $(\mathrm{dT})_{18}$ primer.

\section{PCR amplification of LIAS and positive clonal screening}

The following primers for LIAS were synthesized by Takara (China): forward primer P1, 5'-CGGAATTCATGGCTCTACGCTGCCGGGGC-3' (containing an EcoRI cleavage site), and reverse primer P2, 5'-CCCAAGCTTTTAGAGGGCTTTTGTTTTTC-3' (containing a HindIII cleavage site). Each reaction comprised $16.25 \mu \mathrm{L} \mathrm{ddH}_{2} \mathrm{O}, 0.25 \mu \mathrm{L} 5 \mathrm{U} / \mu \mathrm{L}$ TaKaRa LA Taq polymerase, $2.5 \mu \mathrm{L}$ 10X LA PCR Buffer ( $\mathrm{Mg}^{2+}$ Plus), $4 \mu \mathrm{L} 2.5 \mathrm{mM}$ dNTP mixture, $0.5 \mu \mathrm{L}$ $20 \mu \mathrm{M} \mathrm{P} 1$ and $\mathrm{P} 2$, and $1 \mu \mathrm{L} \mathrm{cDNA}$; the total volume was $25 \mu \mathrm{L}$. The following conditions were used: $95^{\circ} \mathrm{C}$ for $5 \mathrm{~min} ; 35$ cycles of $95^{\circ} \mathrm{C}$ for $30 \mathrm{~s}, 58^{\circ} \mathrm{C}$ for $30 \mathrm{~s}$, and $72^{\circ} \mathrm{C}$ for $70 \mathrm{~s}$; and elongation at $72^{\circ} \mathrm{C}$ for $10 \mathrm{~min}$. The final product from PCR was detected by $1 \%$ agarose electrophoresis and purified by TaKaRa Agarose Gel DNA Purification Kit Ver. 2.0. The product was ligated overnight with the pMD19-T vector at $16^{\circ} \mathrm{C}$. The pMD19-T-Lias clonal vector was constructed and transferred to Escherichia coli DH5a. Isopropyl $\beta$-D-1-thiogalactopyranoside (IPTG) and 5 -bromo-4-chloro-3-indolyl- $\beta$-D-galactopyranoside (X-gal) were used for white-blue plaque selection. The E. coli colonies with a white plaque were selected, and 3 positive clones were chosen for recombinant vector extraction. EcoRI and HindIII double cleavage of the plasmid was carried out, and sample was sent to Sangon (China) for sequencing.

\section{Construction of the $\mathrm{pET}$-28 $\alpha$-Lias prokaryotic expression vector}

pMD19-T-Lias (confirmed by sequencing) was double-digested with EcoRI and HindIII and ligated with pET-28 $\alpha(+)$, and the ligated product was introduced to E. coli BL21 (DE3). The recombinant plasmid that was positive by both plaque PCR and double-enzymatic cleavage was sent to Sangon (China) for sequencing and was named pET-28 $\alpha$-Lias.

\section{Induced expression of pET-28 $\alpha$-Lias}

One hundred microliters $E$. coli with recombinant plasmid was cultured overnight in $1 \mathrm{~mL}$ Luria-Bertani broth (LB) culture medium containing $50 \mu \mathrm{g} / \mathrm{mL}$ kanamycin at $37^{\circ} \mathrm{C}$ with shaking at $220 \mathrm{rpm}$. Immediately after overnight incubation, $1 \mathrm{~mL}$ E. coli was added to $50 \mathrm{~mL}$ LB containing $50 \mu \mathrm{g} / \mathrm{mL}$ kanamycin at $37^{\circ} \mathrm{C}$ and shaking at $220 \mathrm{rpm}$ for further growth. When the absorbance of $E$. coli at $600 \mathrm{~nm}$ reached $0.6,1 \mathrm{~mL}$ non-IPTG-inducing $E$. coli suspension was removed as the negative control. IPTG was added to the remaining E. coli suspension to the final concentration of $1 \mathrm{mM}$, and the induction was carried out at $37^{\circ} \mathrm{C}$ with shaking at 220 $\mathrm{rpm}$. One milliliter suspension was removed at 1, 2, 3, 4, 5, 6, 7, and $8 \mathrm{~h}$ post-induction. All of the samples were centrifuged at $10,000 \mathrm{~g}$ for $10 \mathrm{~min}\left(4^{\circ} \mathrm{C}\right)$, and supernatant was removed. 
The sediments were re-suspended on $100 \mu \mathrm{L} 1 \mathrm{X}$ sodium dodecyl sulfate-polyacrylamide gel electrophoresis (SDS-PAGE) loading buffer and boiled at $100^{\circ} \mathrm{C}$ for $10 \mathrm{~min}$. SDS-PAGE was adopted to detect the protein expression level.

\section{Western blotting of recombinant protein}

The recombinant protein was transferred to a nitrocellulose (NC) membrane at 100 $\mathrm{V}$ for 70 min after SDS-PAGE. After blocking for $1 \mathrm{~h}, 1: 6000$ mouse-anti-6xHis monoclonal antibody (ZSGB-BIO, China) was added and incubated with the NC membrane overnight at $4^{\circ} \mathrm{C}$. After the washing, 1:12,000 HRP-tagged goat-anti-mouse IgG was incubated with the $\mathrm{NC}$ membrane for $1 \mathrm{~h}$. The membrane was visualization by the ECL plus chemiluminescence kit in the dark room.

\section{RESULTS}

\section{Cloning of LIAS}

The amplification results of porcine $L I A S$ were shown in Figure 1. The specific target DNA fragment, which matched the expected fragment size, was extracted and amplified from total RNA of porcine liver by RT-PCR. The length of the PCR product is around $1119 \mathrm{bp}$ and was determined by $1 \%$ agarose electrophoresis. The positive clone that was chosen from the pMD19-T ligation was confirmed by PCR of the E. coli suspension (Figure 2). Sequencing analysis showed that the target gene was porcine $L I A S$, it included a full open reading frame (ORF) of $1119 \mathrm{bp}$, and the gene encoded 372 amino acids in the final protein product. The sequence has been submitted to GenBank with the registration number of JN797612.1. pMD19T-Lias can be cleaved by EcoRI and HindIII into 2 fragments with lengths of 2692 and $1119 \mathrm{bp}$ that were confirmed by PCR and electrophoresis (Figure 3). The lengths of these 2 fragments are consistent with the theoretical length of the target gene.

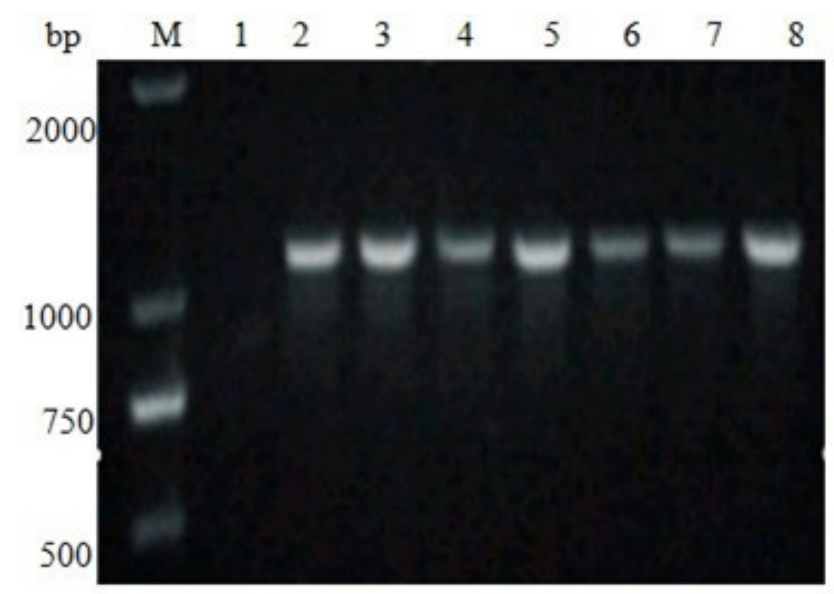

Figure 1. Agarose gel electrophoresis pattern of porcine LIAS PT-PCR amplification. Lane $M=$ DL2000 DNA marker; lane $1=$ negative control; lanes $2-8=$ PCR products of positive recombinant plasmid. 


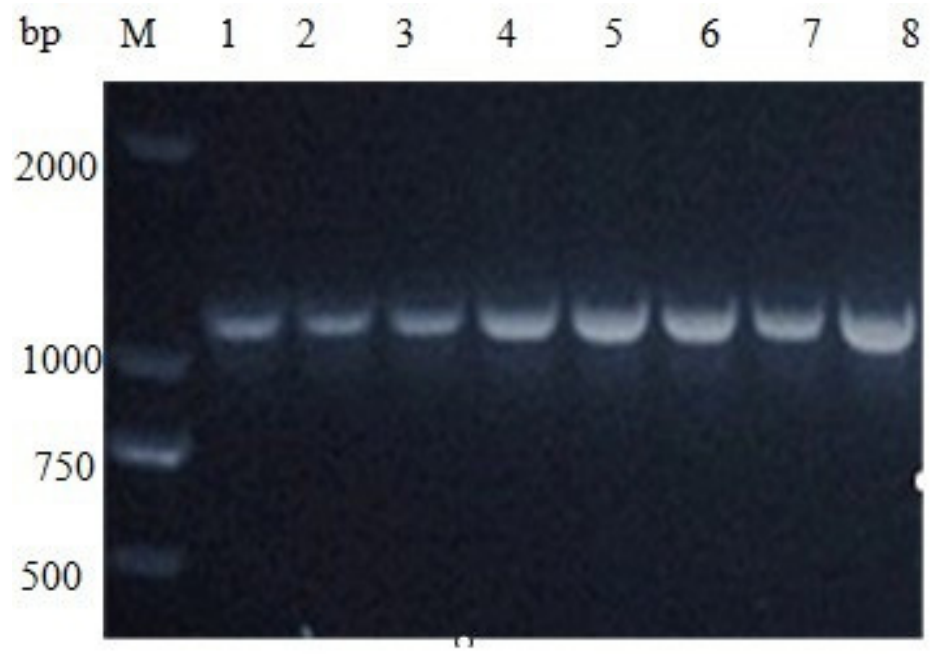

Figure 2. Agarose gel electrophoresis pattern of pMD19-T-LIAS-positive clones. Lane $M=$ DL2000 DNA marker; lanes 1-8 = PCR product of positive recombinant plasmid.

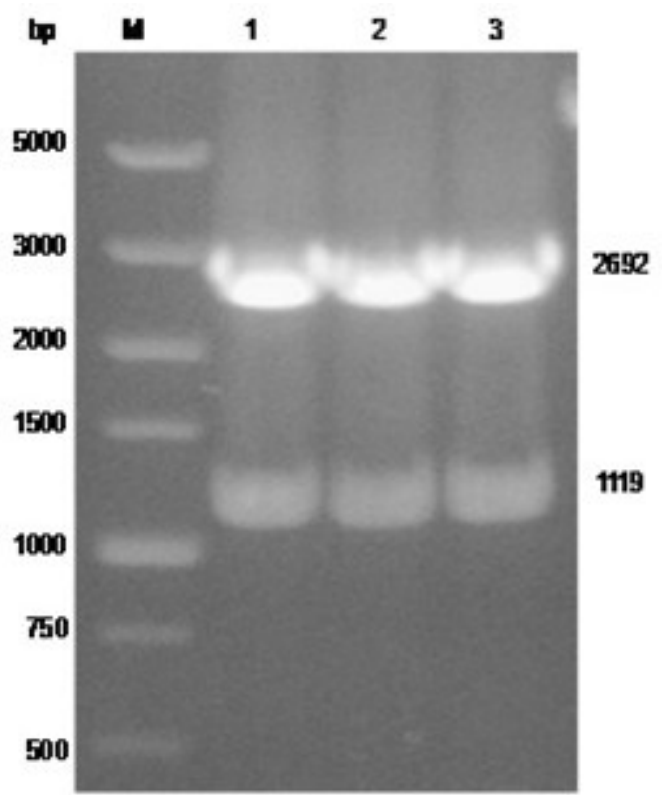

Figure 3. HindIII/EcoRI digestion analysis of pET28-LIAS recombinants. Lane $M=$ DL5000 DNA marker; lanes 1,2 and $3=$ pET28-LIAS candidates digested by HindIII/EcoRI.

\section{Construction of the pET-28a(+)-Lias prokaryotic expression vector}

After digestion with EcoRI and HindIII, pMD19-T-Lias was used for ligation with pET-28 $\alpha(+)$ to construct the recombinant plasmid pET-28 $(+)$-Lias. After the PCR amplifica- 
tion of pET-28 $\alpha(+)$-Lias, the target fragment had a length of 1119 bp. pET-28 $\alpha(+)$-Lias has 3 cleavage sites for the restriction endonuclease $S s p$ I. After $S s p$ I digestion, 3 fragments with lengths of 4498, 1403, and 568 bp were evident by electrophoresis (Figure 4), which confirmed the successful construction of the prokaryotic expression vector pET-28 $\alpha(+)$-Lias.

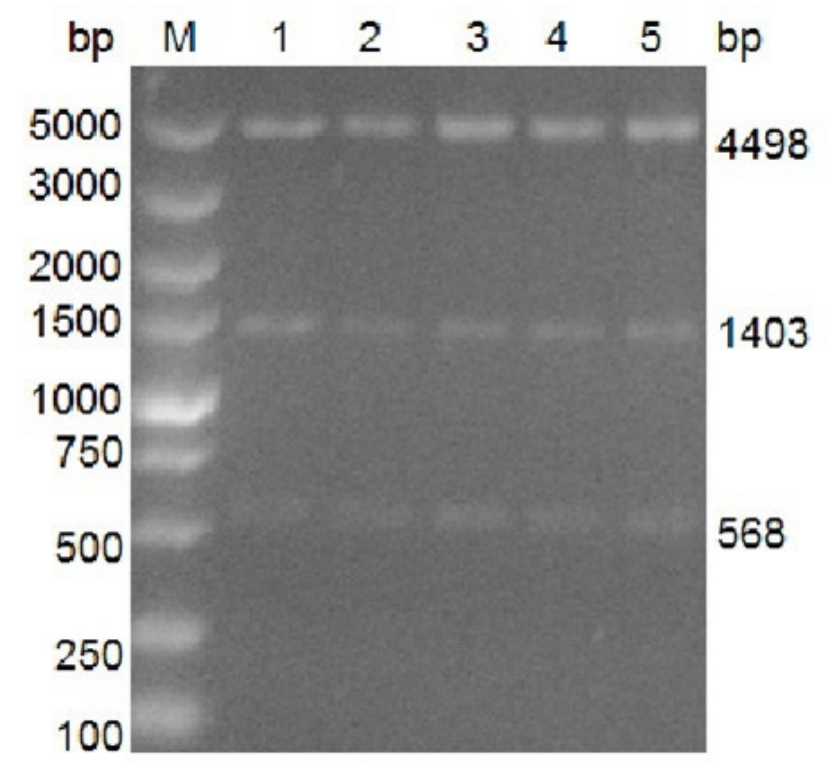

Figure 4. $S s p$ I digestion analysis of pET-28 (+)-LIAS recombinants. Lane $M=$ DL5000 DNA marker; lanes 1, 2 and $3=\mathrm{pET}-28 \alpha(+)$-LIAS recombinants digested by $S s \mathrm{I}$.

\section{Expression of recombinant protein from pET-28 $(+)-$ Lias}

The expression product from pET-28 $\alpha(+)$-Lias by IPTG induction was examined by SDS-PAGE. The electrophoresis bands from SDS-PAGE were stained by Coomassie brilliant blue G-250. A foreign protein band appeared at the molecular weight of $42 \mathrm{kDa}$, which was consistent with theoretical molecular weight of the recombinant protein from pET-28 $\alpha(+)$-Lias. The induction efficiency elevated with increasing induction time and peaked at $8 \mathrm{~h}$ post-induction (Figure 5). The negative control did not have significant expression of the target protein band.

\section{Western blotting analysis of the recombinant protein}

Mouse anti-6xHis monoclonal antibody and HRP-labeled goat anti-mouse IgG were used in Western blotting to identify the expression product of porcine LIAS, and the results were shown in Figure 6. The appearance of a unique band at $42 \mathrm{kDa}$ matched the expected molecular weight of $41.58 \mathrm{kDa}$, and pET-28 $\alpha(+)$-Lias before IPTG induction did not present a protein band at a similar location. Combining these results, the protein that was expressed from pET-28 $\alpha(+)$-Lias after IPTG induction interacted strongly with 6xHis monoclonal antibody, which indicated the expression of the target protein. 


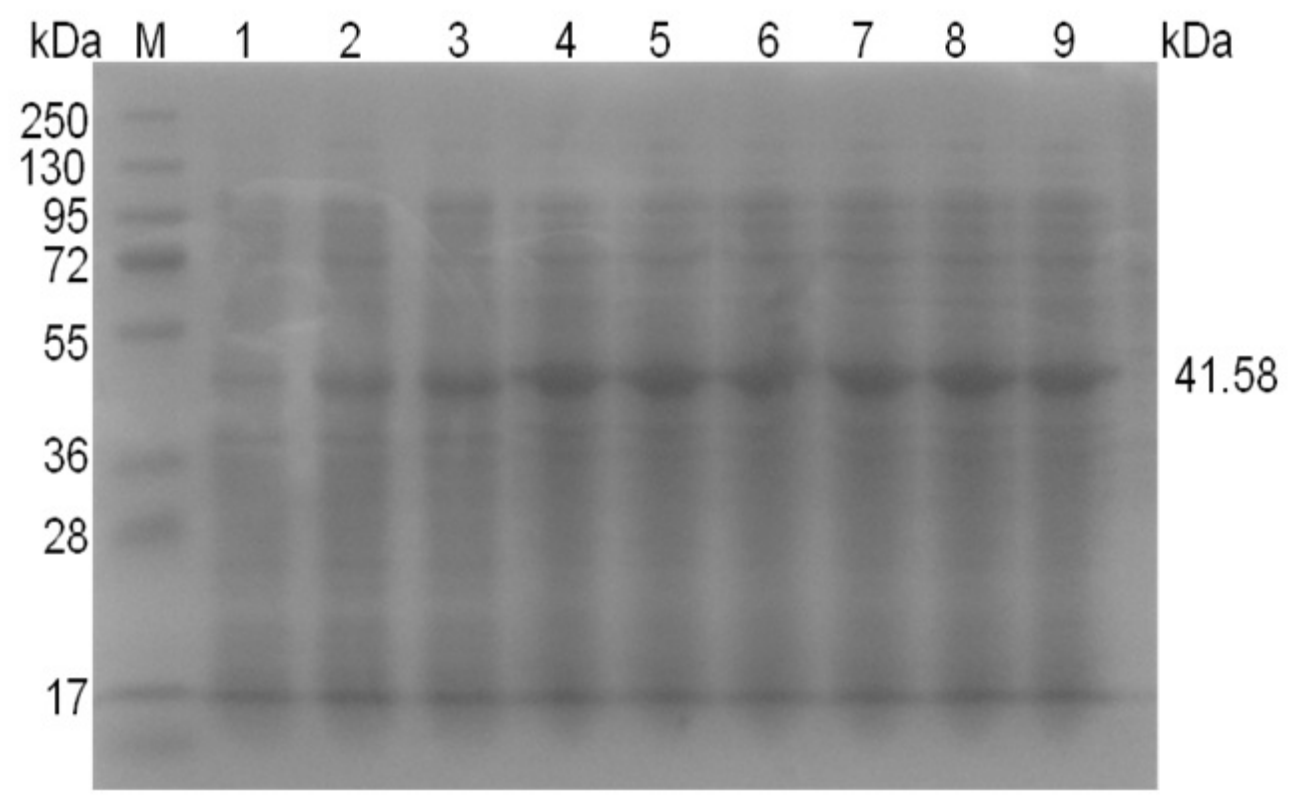

Figure 5. SDS-PAGE of fusion protein expression form of LIAS. Lane $M=$ protein marker; lane 1 = without IPTGinduced fusion protein; lanes 2-9 = with IPTG-induced fusion protein for 1, 2, 3, 4, 5, 6, 7, and $8 \mathrm{~h}$.

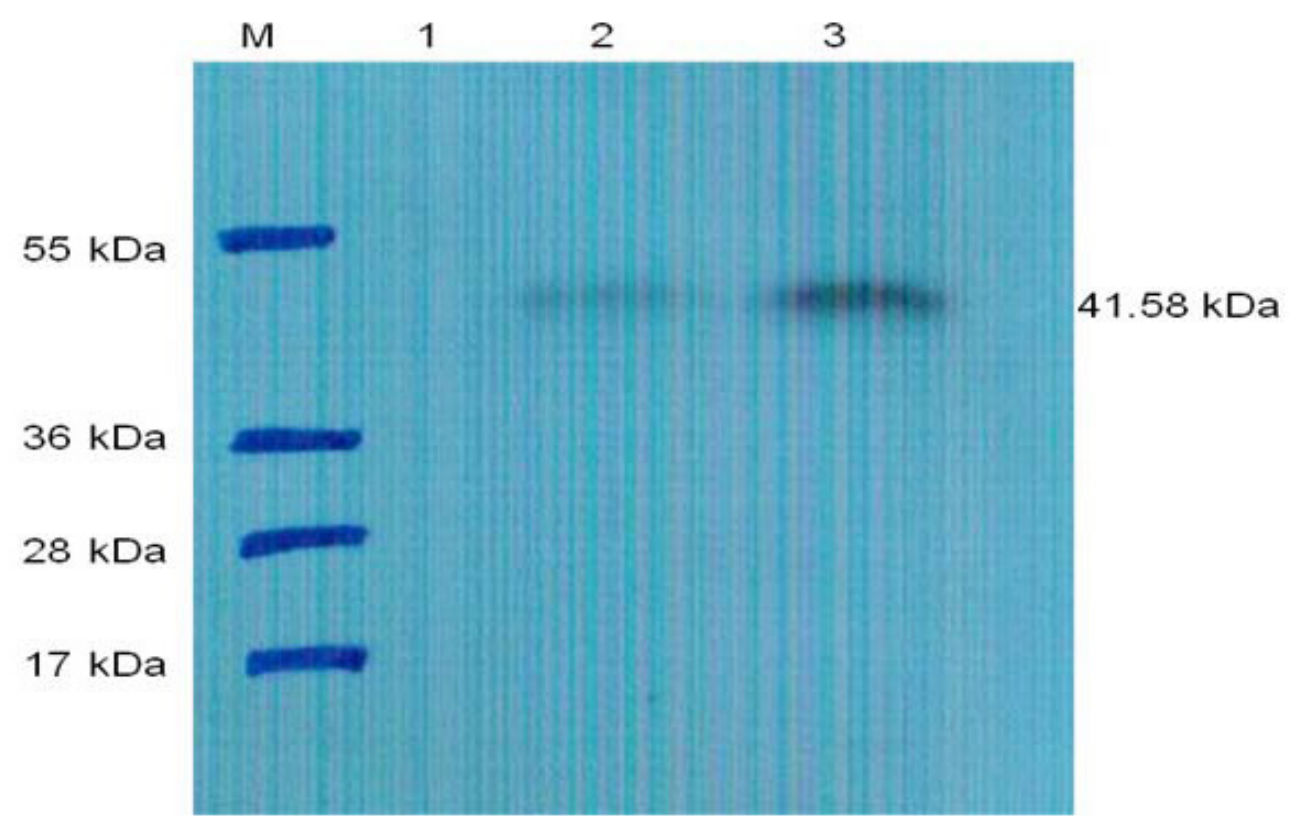

Figure 6. Western blotting analysis of the expression product of pET-28 $\alpha$-LIAS. Lane $M=$ protein marker; lane $1=$ without IPTG-induced fusion protein; lanes 2 and $3=$ with IPTG-induced fusion protein for 3 and $6 \mathrm{~h}$. 


\section{DISCUSSION}

Some research indicated that certain nucleotide polymorphisms in the coding area of porcine LIAS are closely associated with the fat generation capacity in pig, and it can have crucial impacts on fat generation-related gene expression. However, no researchers have constructed the prokaryotic expression vector of the porcine $L I A S$ gene and performed the related protein purification. Because the LIAS gene is involved in the control of fat metabolism, it is greatly significant to study porcine LIAS in detail.

In this study, we used in silico elongation and RT-PCR to amplify the full ORF of porcine LIAS from liver or fat tissues in pig. The ORF is $1119 \mathrm{bp}$ and encodes 372 amino acids (Allary et al., 2007). The prokaryotic expression vector pET-28 $\alpha(+)$-Lias was established successfully via the pET protein expression system. To acquire stable and highly efficient protein expression in large doses, the inducing parameters were optimized. With different inducing concentrations or inducing times of IPTG, we confirmed that a high level of LIAS expression can be achieved in E. coli BL2l (DE3) with an 8-h induction by $1.0 \mathrm{mM} \mathrm{IPTG,} \mathrm{and} \mathrm{the} \mathrm{target}$ protein had a molecular weight of $41.58 \mathrm{kDa}$. The protein was produced in the form of inclusion bodies, and the fusion protein contained a $6 x$ histidine tag, which usually does not interfere with the structure and function of the recombinant protein. The successful establishment of the prokaryotic expression vector pET-28 $\alpha(+)$-Lias along with the efficient expression of the LIAS fusion protein can provide the preliminary data for preparing a monoclonal antibody, constructing a eukaryotic expression vector, and studying the biological functions of LIAS. At the same time, it can serve as the foundation to study other fat metabolism factors. Further studies on the LIAS protein can facilitate the control of fat synthesis in farm animals, which can be used to culture improved species with appropriate levels of fat contents.

\section{ACKNOWLEDGMENTS}

(\#2011CB100802).

\section{REFERENCES}

Allary M, Lu JZ, Zhu L and Prigge ST (2007). Scavenging of the cofactor lipoate is essential for the survival of the malaria parasite Plasmodium falciparum. Mol. Microbiol. 63: 1331-1344.

Christensen QH, Martin N, Mansilla MC, de Mendoza D, et al. (2011). A novel amidotransferase required for lipoic acid cofactor assembly in Bacillus subtilis. Mol. Microbiol. 80: 350-363.

Crawford MJ, Thomsen-Zieger N, Ray M, Schachtner J, et al. (2006). Toxoplasma gondii scavenges host-derived lipoic acid despite its de novo synthesis in the apicoplast. EMBO J. 25: 3214-3222.

Cronan JE, Zhao X and Jiang Y (2005). Function, attachment and synthesis of lipoic acid in Escherichia coli. Adv. Microb. Physiol. 50: 103-146.

Ghibu S, Richard C, Delemasure S, Vergely C, et al. (2008). An endogenous dithiol with antioxidant properties: alphalipoic acid, potential uses in cardiovascular diseases. Ann. Cardiol. Angeiol. 57: 161-165.

Hiltunen JK, Autio KJ, Schonauer MS, Kursu VA, et al. (2010). Mitochondrial fatty acid synthesis and respiration. Biochim. Biophys. Acta 1797: 1195-1202.

Holmquist L, Stuchbury G, Berbaum K, Muscat S, et al. (2007). Lipoic acid as a novel treatment for Alzheimer's disease and related dementias. Pharmacol. Ther. 113: 154-164.

Melhem MF, Craven PA, Liachenko J and DeRubertis FR (2002). Alpha-lipoic acid attenuates hyperglycemia and prevents glomerular mesangial matrix expansion in diabetes. J. Am. Soc. Nephrol. 13: 108-116. 
Morikawa T, Yasuno R and Wada H (2001). Do mammalian cells synthesize lipoic acid? Identification of a mouse cDNA encoding a lipoic acid synthase located in mitochondria. FEBS Lett. 498: 16-21.

Morris TW, Reed KE and Cronan JE Jr (1994). Identification of the gene encoding lipoate-protein ligase A of Escherichia coli. Molecular cloning and characterization of the lplA gene and gene product. J. Biol. Chem. 269: 16091-16100.

Packer L, Kraemer K and Rimbach G (2001). Molecular aspects of lipoic acid in the prevention of diabetes complications. Nutrition 17: 888-895.

Rock CO (2009). Opening a new path to lipoic acid. J. Bacteriol. 191: 6782-6784.

Sulo P and Martin NC (1993). Isolation and characterization of LIP5. A lipoate biosynthetic locus of Saccharomyces cerevisiae. J. Biol. Chem. 268: 17634-17639.

Yi X and Maeda N (2005). Endogenous production of lipoic acid is essential for mouse development. Mol. Cell Biol. 25: 8387-8392. 